\title{
WYZNACZANIE WARTOŚCI WYPRACOWANEJ W INWESTYCJACH REALIZOWANYCH PRZEZ PODWYKONAWCÓW
}

\begin{abstract}
Metoda EVM umożliwia efektywną kontrolę inwestycji budowlanych za pomocą wskaźnika wartości wypracowanej. Wskaźniki określają rzeczywistą wartość wypracowaną wykonanych robót. Poprawne wyznaczenie tego wskaźnika jest podstawowym zadaniem analizy EVM. Na podstawie analizy konwencjonalnych rozwiązań, zbadano zastosowanie metody EVM dla inwestycji wykonywanych głównie przez podwykonawców. Wyniki zrealizowanych badań potwierdzają, że zastosowanie metod EVM do kontroli takich inwestycji wymaga korekty wskaźników wartości wypracowanej.
\end{abstract}

Słowa kluczowe: zarządzanie wartością wypracowaną, koszty, inwestycje budowlane, podwykonawcy

\section{Wprowadzenie}

Kontrola cyklu realizacji inwestycji budowlanych jest jednym z warunków koniecznych wykonania robót na czas, w ramach budżetu i zgodnie z oczekiwaniami inwestora. Metoda EVM jest jedną z metod kontroli inwestycji, która jest szczególnie przydatna w fazie realizacji robót na placu budowy. Pozwala określić stopień zaawansowania robót w czasie i zgodnie z nim kontrolować budżet inwestycji. Umożliwia również określenie opóźnienia lub przyspieszenia robót w czasie [1]. Poprawne wyznaczenie wskaźnika wartości wypracowanej dla konkretnej inwestycji budowlanej umożliwia realne śledzenie postępu robót i podejmowanie właściwych decyzji operatywnych. Analizie poddano inwestycje, w których większość robót realizują podwykonawcy. Natomiast kontrola rzeczowo - finansowa przedsięwzięcia przeprowadzana jest na poziomie generalnego wykonawcy.

\footnotetext{
${ }^{1}$ Autor do korespondencji/corresponding author: Anna Starczyk, Wydział Inżynierii Lądowej i Geodezji, Wojskowa Akademia Techniczna w Warszawie, ul. Kaliskiego 2, 00-908 Warszawa, anna.starczyk@wat.edu.pl

2 Tadeusz Kasprowicz, Wydział Inżynierii Lądowej i Geodezji, Wojskowa Akademia Techniczna w Warszawie, ul. Kaliskiego 2, 00-908 Warszawa, tadeusz.kasprowicz@wat.edu.pl
} 


\section{Metody wyznaczania wartości wypracowanej}

Aktualnie stosowana metoda EVM znajduje zastosowanie przy kontroli przedsięwzięć budowlanych na poziomie wykonawcy budowy [2]. Rzeczywistym poniesionym kosztem AC są wtedy faktury kosztowe wykonawcy, w których skład wchodzą m.in. faktury za materiały, sprzęt, transport, które w danym okresie rozliczeniowym (np. w tym samym miesiącu) nie powodują wzrostu kosztu wykonania planowanych prac EV. W związku z powyższym dwa z głównych wskaźników metody EVM różnią się od siebie, czyli EV $\neq$ AC. Dzięki temu możemy za pomocą tej metody kontrolować inwestycję, stwierdzić przyspieszenie lub opóźnienie robót. Obrazuje to poniższy wykres. Klasyczna analiza EVM może być zrealizowana w następujących kolejnych krokach [3]:

1. Zidentyfikować, jakie roboty wykonano i jakie powinny być wykonane.

2. Określić, jak dużo pieniędzy zarobiono (EV) i ile pieniędzy wydano (AC).

3. Obliczyć czas (harmonogram) i pieniądze (budżet) oraz określić istniejące rozbieżności (CV=EV-AC, SV=EV-PV, CPI=EV/AC, SPI=EV/PV).

4. Przeanalizować przyczyny głównych różnic oraz określić ewentualne środki zaradcze.

5. Ekstrapolować istniejące różnice do zakończenia projektu.

Sytuacja ulega zmianie, gdy większość robót wykonują podwykonawcy. To oni ponoszą koszty m.in. zakupu materiałów, transportu, sprzętu. Rzeczywistym poniesionym kosztem AC generalnego wykonawcy stają się w głównym stopniu faktury podwykonawców rozliczane na podstawie zaawansowania robót. Dodatkowymi kosztami rzeczywistymi ponoszonymi przez generalnego wykonawcę

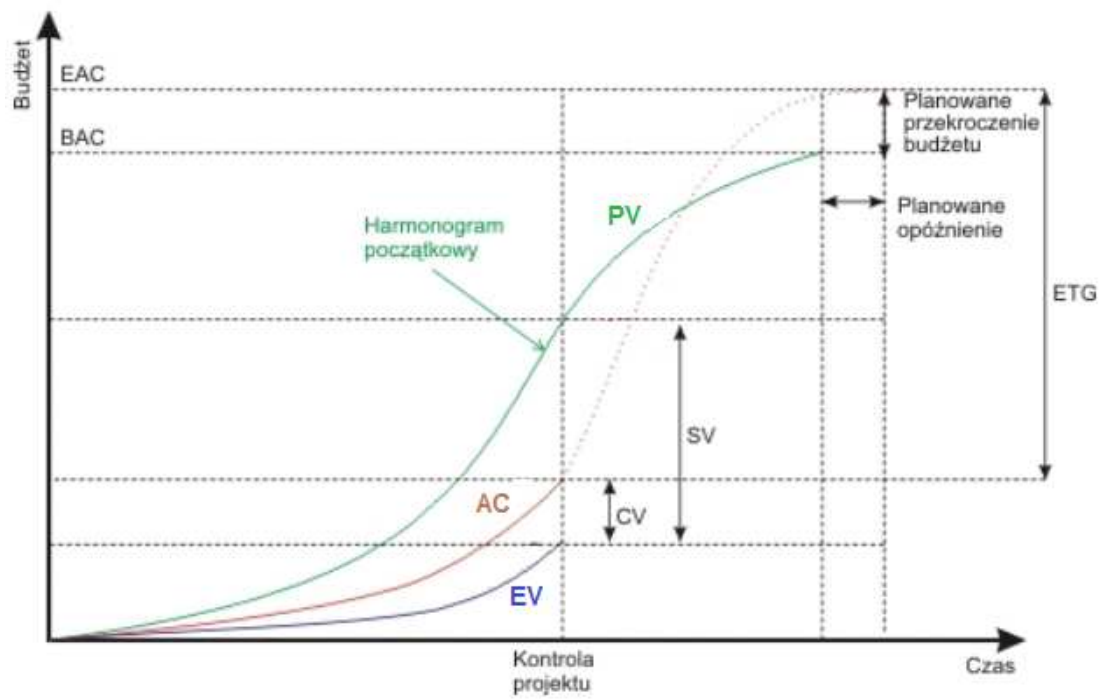

Rys. 1. Podstawowe wskaźniki EVM, na podstawie [4]

Fig. 1. Basic EVM indicators, based on [4] 
są koszty zatrudnienia osób nadzorujących zaawansowanie robót, którzy na tej podstawie sporządzają protokoły częściowe robót $\mathrm{z}$ wyliczoną kwotą wykonanych prac oraz niewielkie koszty prac realizowanych własnymi siłami, stanowiące ok. $10 \%$ inwestycji.

Wartością wypracowaną EV w tym przypadku są koszty wykonanych robót, rozliczone na podstawie sporządzonego protokołu odbioru, który określa stopień zaawansowania robót zgodnie z obmiarem. Protokoły odbioru są sporządzane między inwestorem a generalnym wykonawcą oraz między generalnym wykonawcą a podwykonawcami. Stopień zaawansowania robót jest taki sam, różni się jedynie cena jednostkowa wykonanych robót przyjmowana do rozliczeń częściowych przez generalnego wykonawcę a podwykonawców. Na tej podstawie dokonano rozróżnienia w sposobie określania wielkości EV. Iloczyn ceny jednostkowej i obmiaru wykonanych robót daje wartość wypracowaną. Wartość wypracowana rozliczana przez generalnego wykonawcę (nazwana EV1) jest większa kwotowo od tej, którą ,wykonał” podwykonawca (nazwana EV2). Należy zastanowić się która wartość powinna być wzięta przy kontroli inwestycji metodą EVM w celu uzyskania poprawnych wyników.

Z wyborem określonej wartości wypracowanej EV1 lub EV2 wiąże się też wybór odpowiedniej wartości kosztów planowanych. Koszt planowany ustalony na podstawie sporządzonego harmonogramu czasowo-finansowego generalnego wykonawcy będzie zawierał głównie kwoty planowanych faktur podwykonawców, czyli będzie to PV2. Natomiast planowane kwoty rozliczeń między inwestorem a generalnym wykonawcą to PV1.

Patrząc z perspektywy generalnego wykonawcy, monitorowanie kosztów, polega na kontroli faktur kosztowych wystawionych przez podwykonawców oraz faktur przychodowych, wystawionych przez generalnego wykonawcę dla zamawiającego.

\section{Weryfikacja metod na przykładach zrealizowanych inwesty- cji budowlanych}

Weryfikacji zostały poddane dwie metody wyznaczania wartości wypracowanej EV1 i EV2 w kolejnych miesiącach kontroli inwestycji. Analizowano trzy różne inwestycje budowlane wykonywane głównie przez podwykonawców. Inwestycja nr 1 to budowa pawilonu mieszkalnego w latach 2008 - 2010 [5]. Inwestycja $\mathrm{nr} 2$ to budowa pawilonu tymczasowego zakwaterowania w latach 2010 - 2012. Natomiast inwestycja nr 3 to kompleksowa termomodernizacja pawilonów mieszkalnych w latach 2013-2015.

W opracowaniu przedstawiono wyniki badań dla jednej inwestycji, z uwagi na fakt, iż dwie kolejne dały bardzo zbliżone wyniki, potwierdzając tym samym prawidłowość założen.

Dla wartości trzech podstawowych parametrów wyznaczonych za pomocą metody $\mathrm{nr} 1$ i $\mathrm{nr} 2$ sporządzono wykresy w poszczególnych miesiącach kontroli umożliwiające porównanie dwóch metod. 
Tabela 1. Zestawienie trzech podstawowych parametrów metody EVM w poszczególnych miesiącach realizacji budowy nr 1 wyznaczonych przy użyciu metody $\mathrm{nr} 1$ i metody $\mathrm{nr} 2$ [5]

Table 1. Record of the basic parameters of EVM method in the following months on construction No. 1, calculated using methods No. 1 and No. 2 [5]

\begin{tabular}{|c|c|c|c|c|c|}
\hline $\begin{array}{c}\text { Czas } \\
\text { [miesiące] }\end{array}$ & EV1 & EV2 & AC & PV1 & PV2 \\
\hline XI 2008 & $400000,00 \mathrm{zł}$ & $393760,00 \mathrm{zł}$ & $423490,00 \mathrm{zł}$ & $400000,00 \mathrm{zł}$ & $368000,00 \mathrm{zł}$ \\
\hline XII 2008 & $1241705,00 \mathrm{zł}$ & $1222475,00 \mathrm{zł}$ & $1281935,00 \mathrm{zł}$ & $1241705,00 \mathrm{zł}$ & $1142500,00 \mathrm{zł}$ \\
\hline I 2009 & $1241705,00 \mathrm{zł}$ & $1222475,00 \mathrm{zł}$ & $1281935,00 \mathrm{zł}$ & $1241705,00 \mathrm{zł}$ & $1142500,00 \mathrm{zł}$ \\
\hline II 2009 & $1537455,00 \mathrm{zł}$ & $1513515,00 \mathrm{zł}$ & $1572975,00 \mathrm{zł}$ & $1537455,00 \mathrm{zł}$ & $1414500,00 \mathrm{zł}$ \\
\hline III 2009 & $2689974,13 \mathrm{zł}$ & $2589400,00 \mathrm{zł}$ & $2648860,00 \mathrm{zł}$ & $2689974,13 \mathrm{zł}$ & $2420000,00 \mathrm{zł}$ \\
\hline IV 2009 & $3420974,13 \mathrm{zł}$ & $3247985,00 \mathrm{zł}$ & $3307445,00 \mathrm{zł}$ & $3420974,13 \mathrm{zł}$ & $3035500,00 \mathrm{zł}$ \\
\hline V 2009 & $4420974,13 \mathrm{zł}$ & $4116370,00 \mathrm{zł}$ & $4175830,00 \mathrm{zł}$ & $4420974,13 \mathrm{zł}$ & $3700000,00 \mathrm{zł}$ \\
\hline VI 2009 & $5450672,08 \mathrm{zł}$ & $4985050,16 \mathrm{zł}$ & $5044510,16 \mathrm{zł}$ & $5450672,08 \mathrm{zł}$ & $4600000,00 \mathrm{zł}$ \\
\hline VII 2009 & $6443142,04 \mathrm{zł}$ & $6016846,35 \mathrm{zł}$ & $6076306,35 \mathrm{zł}$ & $5746142,04 \mathrm{zł}$ & $5400000,00 \mathrm{zł}$ \\
\hline VIII 2009 & $7123142,04 \mathrm{zł}$ & $6457258,35 \mathrm{zł}$ & $6516718,35 \mathrm{zł}$ & $6267244,54 \mathrm{zł}$ & $6200000,00 \mathrm{zł}$ \\
\hline IX 2009 & $7806460,45 \mathrm{zł}$ & $7114364,25 \mathrm{zł}$ & $7173824,25 \mathrm{zł}$ & $6853546,86 \mathrm{zł}$ & $6900000,00 \mathrm{zł}$ \\
\hline X 2009 & $8329450,45 \mathrm{zł}$ & $7827830,18 \mathrm{zł}$ & $7887290,18 \mathrm{zł}$ & $7460001,00 \mathrm{zł}$ & $7600000,00 \mathrm{zł}$ \\
\hline XI 2009 & $8784450,45 \mathrm{zł}$ & $8279450,83 \mathrm{zł}$ & $8338910,83 \mathrm{zł}$ & $8090392,49 \mathrm{zł}$ & $8000000,00 \mathrm{zł}$ \\
\hline XII 2009 & $9158726,04 \mathrm{zł}$ & $8632142,75 \mathrm{zł}$ & $8691602,75 \mathrm{zł}$ & $8503308,12 \mathrm{zł}$ & $8200000,00 \mathrm{zł}$ \\
\hline I 2010 & $9158726,04 \mathrm{zł}$ & $8635802,75 \mathrm{zł}$ & $8695262,75 \mathrm{zł}$ & $8603308,12 \mathrm{zł}$ & $8356586,00 \mathrm{zł}$ \\
\hline II 2010 & $9158726,04 \mathrm{zł}$ & $8635802,75 \mathrm{zł}$ & $8695262,75 \mathrm{zł}$ & $9387044,05 \mathrm{zł}$ & $8515291,00 \mathrm{zł}$ \\
\hline III 2010 & $9360191,08 \mathrm{zł}$ & $8659182,95 \mathrm{zł}$ & $8718642,95 \mathrm{zł}$ & $9387044,05 \mathrm{zł}$ & $8659182,95 \mathrm{zł}$ \\
\hline IV 2010 & $9482868,70 \mathrm{zł}$ & $9083379,41 \mathrm{zł}$ & $9083379,41 \mathrm{zł}$ & $9482868,70 \mathrm{zł}$ & $9083379,41 \mathrm{zł}$ \\
\hline
\end{tabular}

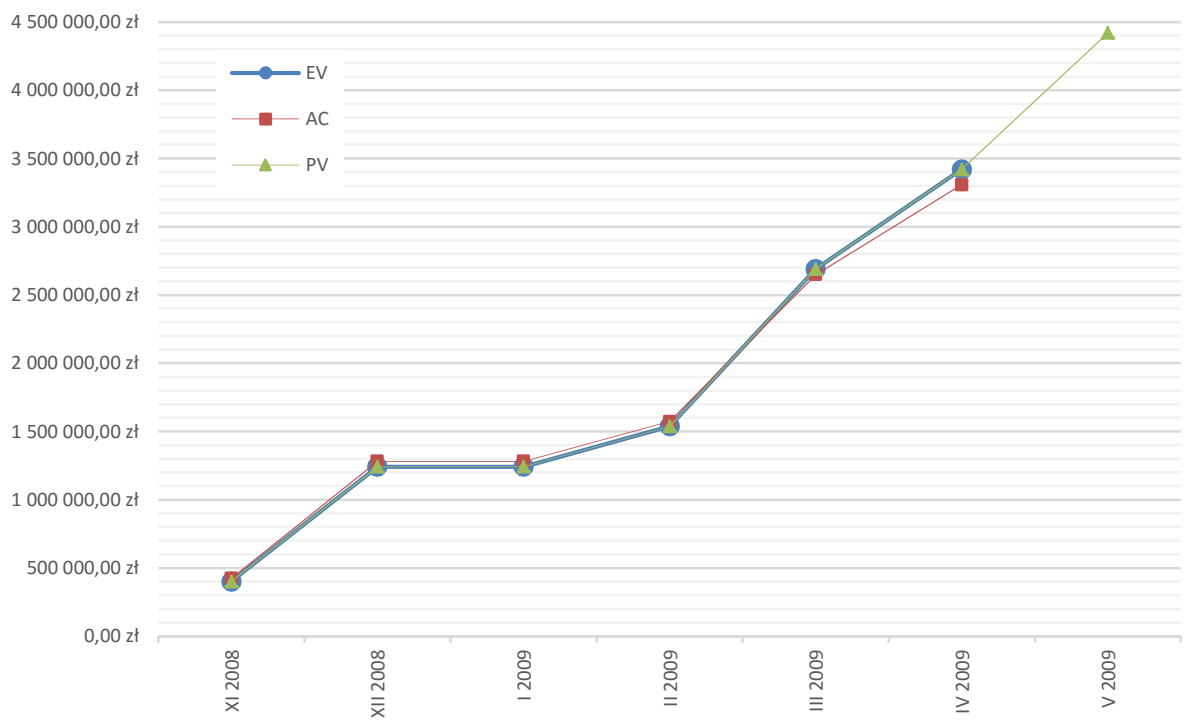

Rys. 2. Podstawowe wskaźniki metody EVM w 6. miesiącu realizacji inwestycji $\mathrm{nr} 1$ obliczone przy użyciu metody nr 1 [opracowanie własne]

Fig. 2. Basic indicators of EVM method in 6th month implementation of investment No. 1, calculated using No. 1 method 


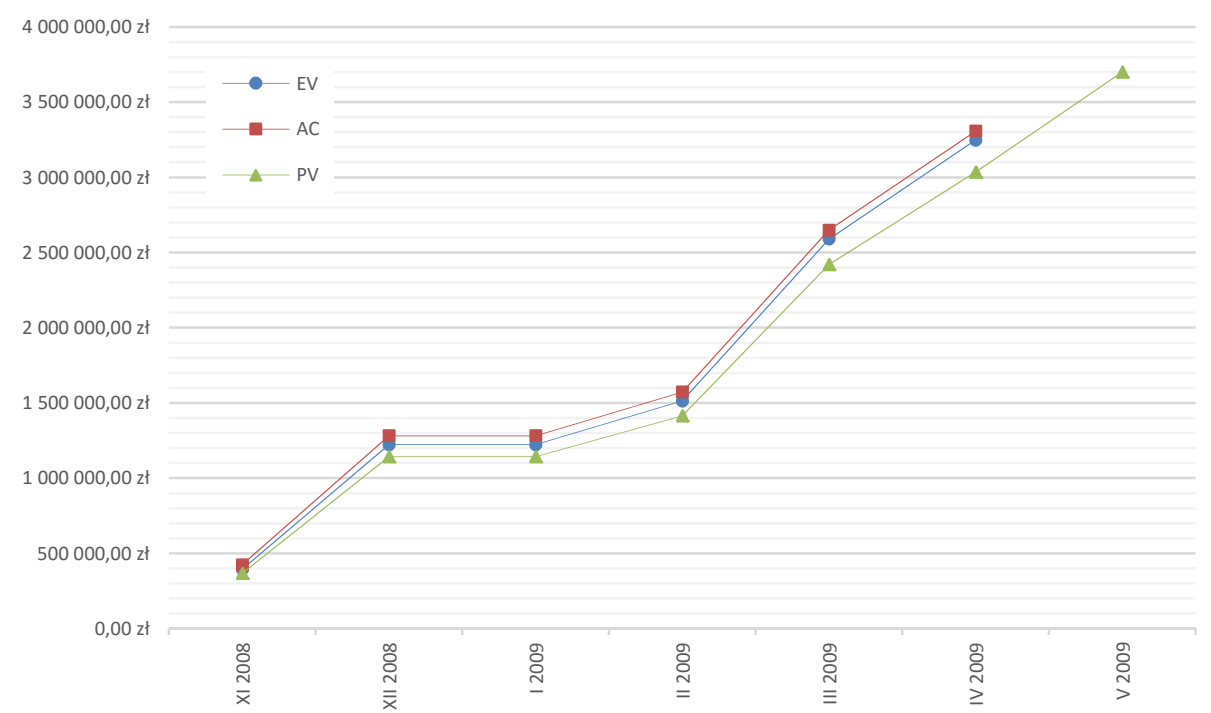

Rys. 3. Podstawowe wskaźniki metody EVM w 6. miesiącu trwania inwestycji nr 1 obliczone przy użyciu metody nr 2 [opracowanie własne]

Fig. 3. Basic indicators of EVM method in 6th month implementation of investment No. 1, calculated using No. 2 method

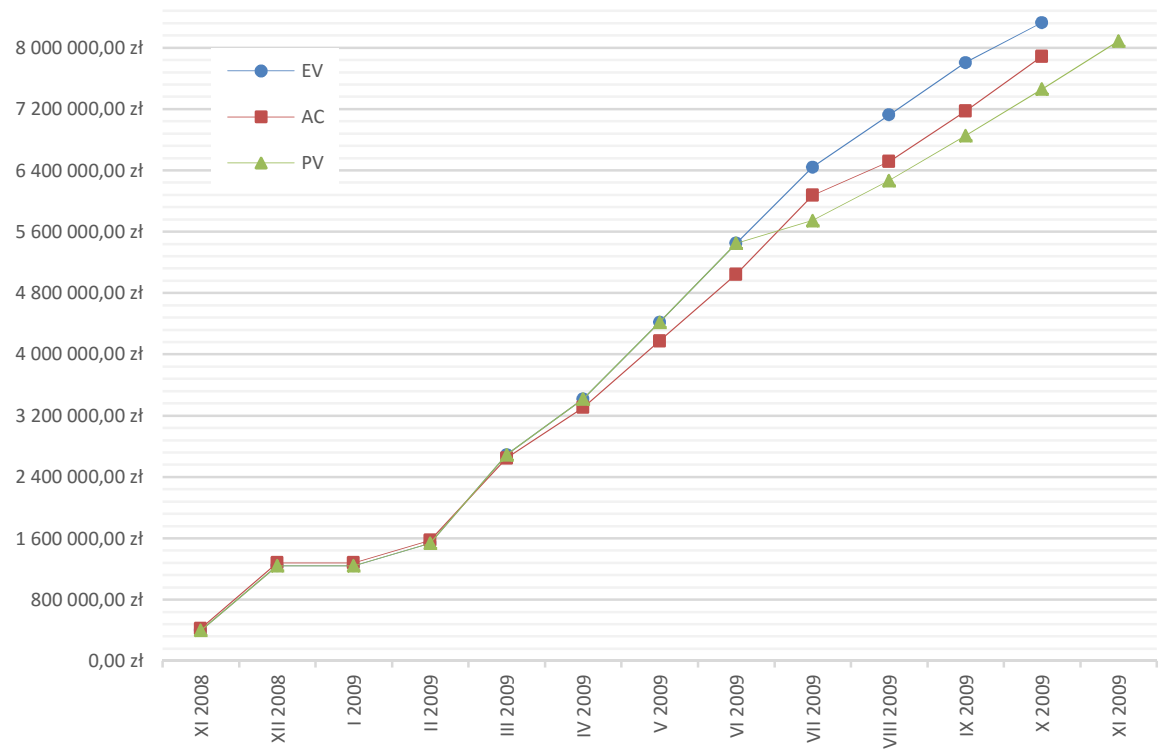

Rys. 4. Podstawowe wskaźniki metody EVM w 12 miesiącu realizacji inwestycji nr 1 obliczone przy użyciu metody nr 1 [opracowanie własne]

Fig. 4. Basic indicators of EVM method in 12th month implementation of investment No. 1, calculated using No. 1 method 


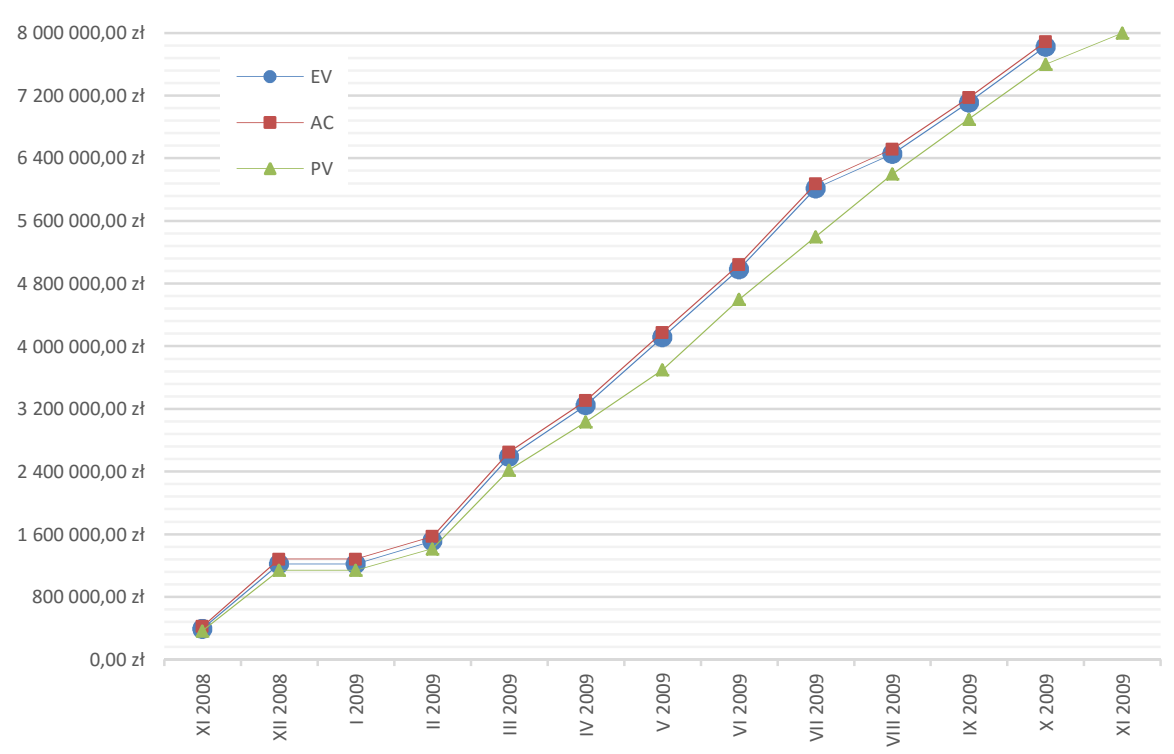

Rys. 5. Podstawowe wskaźniki EVM w 12 miesiącu realizacji inwestycji nr 1 obliczone przy użyciu metody $\mathrm{nr} 2$ [opracowanie własne]

Fig. 5. Basic indicators of EVM method in 12th month implementation of investment No. 1, calculated using No. 2 method

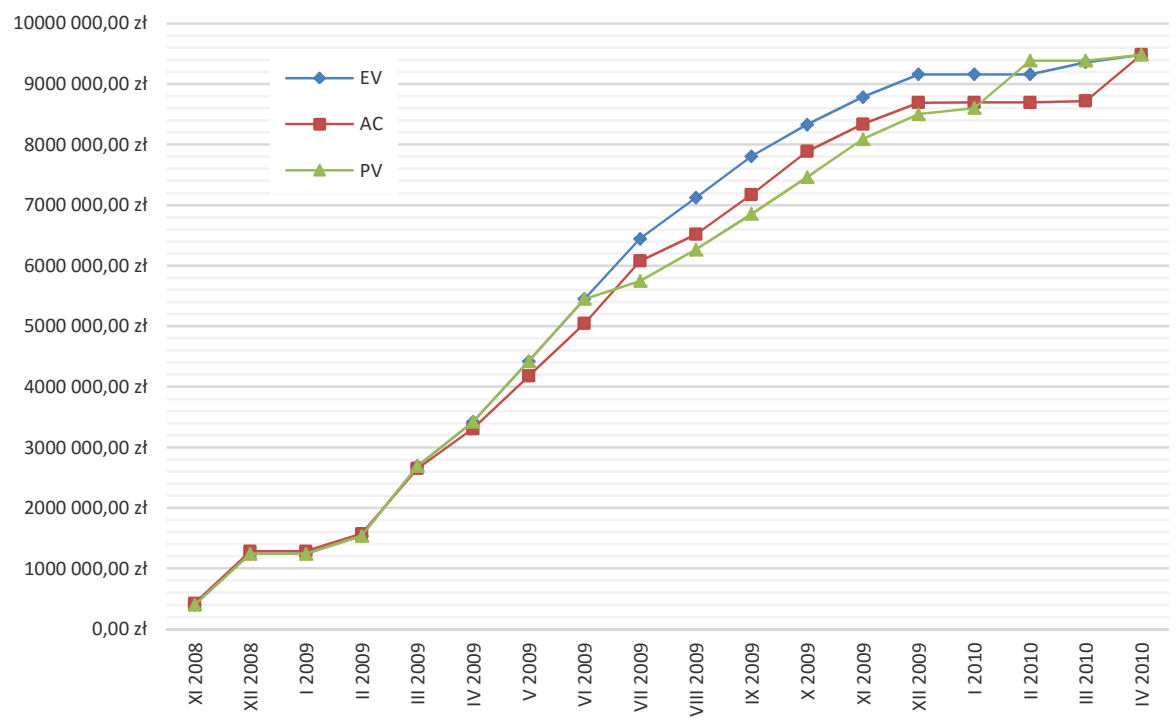

Rys. 6. Podstawowe wskaźniki EVM w 18 miesiącu trwania inwestycji nr 1 obliczone przy użyciu metody $\mathrm{nr} 1$ [opracowanie własne]

Fig. 6. Basic indicators of EVM method in 18th month implementation of investment No. 1, calculated using No. 1 method 


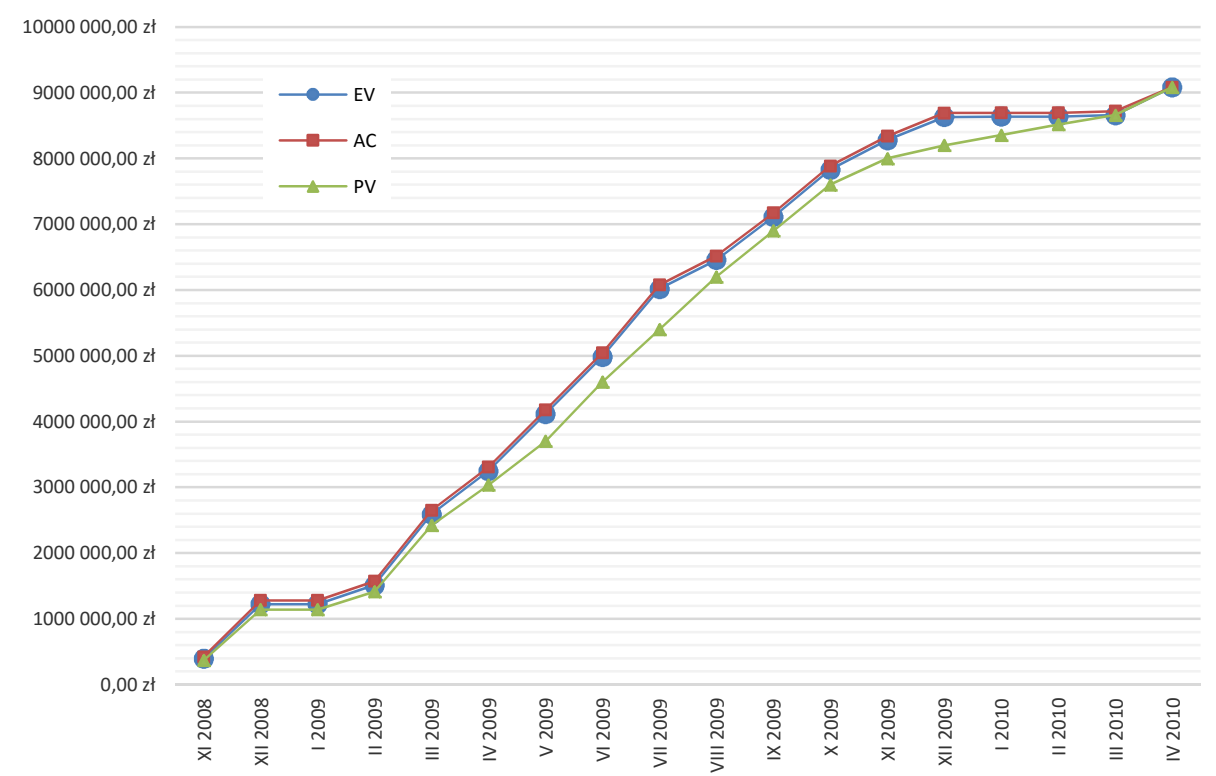

Rys. 7. Podstawowe wskaźniki EVM w 18 miesiącu trwania inwestycji nr 1 obliczone przy użyciu metody $\mathrm{nr} 2$ [opracowanie własne]

Fig. 7. Basic indicators of EVM method in 18th month implementation of investment No. 1, calculated using No. 2 method

\section{Wnioski}

Można zauważyć, iż wartość wskaźnika EV wyznaczona metodą nr 1 jest na każdym etapie kontroli wyższa od wartości wskaźnika AC w sposób widocznie jednostajny, co pozwala kontrolować zysk budowy. Kontrola inwestycji, w której do wyznaczania wskaźników wykorzystano metodę nr 2, pokazuje znacznie mniejsze rozbieżności między wartościami EV i AC w każdej z dokonanych kontroli. W przypadku, gdy EV = AC, metoda EVM straci sens - zacznie przypominać tradycyjną metodę kontroli inwestycji, w której dysponujemy tylko dwoma wskaźnikami: kosztem planowanym PV oraz kosztem rzeczywistym AC.

Na podstawie przeprowadzonych badań, można stwierdzić, iż do wyznaczania wartości wypracowanej EV w inwestycjach wykonywanych głównie przez podwykonawców, gdzie kontrola rzeczowo-finansowa przeprowadzana jest $\mathrm{z}$ poziomu generalnego wykonawcy, należałoby stosować metodę $\mathrm{nr} 1$. Oprócz możliwości, które daje kontrola inwestycji metodą EVM, metoda nr 1 pozwala kontrolować także zysk generalnego wykonawcy, monitorując koszty i przychody inwestycji. 


\title{
Literatura
}

[1] ANSI EIA - 748 Standard - Earned Value Management Systems.

[2] Grobler K.: Ocena projektu metodą Earned Value w systemie IFS Applications, Krakowska konferencja młodych uczonych 2009, s. 45 - 54.

[3] Mubarak Saleh A., Construction Project Scheduling and Control. John Wiley \& Sons, 2015. ISBN: 978-1-118-84600-1, pp. 504.

[4] Połoński M., Komanderek P.: Bieżąca kontrola kosztów realizacji obiektu budowlanego metodą Earned Value, Metody ilościowe w badaniach ekonomicznych, Tom XII/2, 2011, s. 279-290.

[5] Starczyk A.: Wybrane problemy budownictwa, Analiza procesu realizacji przedsięwzięć budowlanych wielokrotnie aneksowanych, Wydawnictwo Uczelniane Uniwersytetu Technologiczno - Przyrodniczego w Bydgoszczy, Bydgoszcz 2015.

\section{CALCULATION OF EARNED VALUE FOR INVESTMENTS IMPLEMENTED MAINLY BY SUBCONTRACTORS}

\begin{abstract}
S u m m a r y
EVM method allows effective control of construction investments by using earned value indicators. The indicators determine the actual earned value of the executed project. The correct calculation of these indicators is the basic task of the EVM analysis. Based on an analysis of conventional solutions, the use of EVM method has been examined for investments implemented mainly by subcontractors. The results of the realized studies confirm that the use of EVM method to such investments requires correction of earned value indicators.
\end{abstract}

Keywords: Earned Value Management, cost, construction investment, subcontractors

Przestano do redakcji: 07.06.2016 r.

Przyjęto do druku: 30.06 .2016 r.

DOI: $10.7862 / r b .2016 .24$ 